Severe haemorrhage occurred in $26.6 \%$ of the present series and required on average over 31 . of blood for replacement. This is wholly unlike the experience in Britain. In the series previously reported by Edmunds ${ }^{2}$ bleeding occurred in $15 \%$ and was nearly always minimal or occult. Recent measurements of occult loss of blood in 26 patients with hiatus hernia have shown that there was a mean loss of 15 ml. per day in anaemic patients and a mean loss of $3 \mathrm{ml}$. per day in those without anaemia. ${ }^{3}$ In Palmer's series a frequent association of both gall stones and diverticular disease with hiatus hernia was found $(10.2 \%$ ). It was rare for only two of these lesions to be present without the third. Hence the author believes it to be more than a chance association and favours the eponym "Saint's triad" for it.

The differentiation of oesophageal and cardiac pain is sometimes difficult, especially in those patients in whom both hiatus hernia and coronary artery disease are present, for the site of the pain and its radiation may be identical. The majority of those patients with reflux will use an adjective suggesting heat to describe their pain, whereas those with cardiac pain will usually describe constriction. However, in a minority it may be virtually impossible to decide from the history. Eome help may be gained from infusing N/10 hydrochloric acid into the oesophagus, for this will reproduce pain due to gastro-oesophageal reflux, ${ }^{4}$ but it may also cause reflex myocardial ischaemia. ${ }^{5}$

There is wide agreement that reduction of weight is a most effective means of controlling heartburn, and patients soon learn to avoid tight clothing, stooping, and lying flat in bed. Antacids and frequent small meals to avoid overdistending the stomach usually produce some symptomatic relief, but Palmer found them to be ineffective. ${ }^{1}$ Indeed, he believes that reflux of gastric contents is not responsible for the oesophagitis-an unorthodox view not shared by most authors, ${ }^{6-8}$ but he offers no clear alternative explanation. Squamous epithelium has little natural powers of resistance to withstand erosion by acid and pepsin. Once reflux of gastric contents occurs, ulceration may rapidly follow, and it will as rapidly heal once contact with gastric juice ceases. A similar sequence of events may be observed in the squamous epithelium of the skin surrounding a gastric fistula. The peptic ulceration usually consists of irregular ulcers which do not penetrate the muscularis mucosae ; but occasionally deep penetrating ulcers are found, usually in relationship to areas of columnar mucosa. These ulcers are likely to develop serious complications-for example, haemorrhage or perforation. ${ }^{7}$ The columnar mucosal lining is probably an acquired lesion. ${ }^{10}$

Only 3.9\% of Palmer's series of patients underwent surgical treatment, and the most frequent indication was serious haemorrhage. Again, experience in Britain is considerably

1 Palmer, E. D., Amer. f. Med., 1968, 44, 566.

- Edmunds, V., Quart. f. Med., 1957, 26, 445.

- Holt, J. M., Mayet, F. G. H., Warner, G. T., Callender, S. T., and Gunning, A. J., Brit. med. F., 1968, 3, 22.

- Bennett, J. R., and Atkinson, M., Gut, 1966, 7, 105.

- Morris, J. C., Shelburne, P. F., and Orgain, E. S., f. Amer. med. Ass., 1963, 183, 788.

- Allison, P. R., Surg. Gynec. Obstet., 1951, 92, 419.

, Sandry, R. J., Gut, 1962, 3, 189.

- Aylwin, J. A., Thorax, 1953, 8, 38.

- Barrett, N. R., Brit. F. Surg., 1950, 38, 175.

10 Adler, R. H., Int. Abstr. Surg., 1963, 116, 1.

1 Collis, J. L., Amer. f. Surg., 1968, 115, 465.

12 Skinner, D. B., and Belsey, R. H. R., F. thorac. cardiovasc. Surg., 1967, 53, 33 .

13 Belsey, R., Proc. roy. soc. Med., 1966, 59, 32.
14 Tanner, N. C., and Westerholm, P., Amer. F. Surg., 1968, 115, 449. different: 23 out of $145(16 \%)$ patients with sliding hiatus hernia underwent operation for symptoms that were not controlled by medical measures. ${ }^{2}$ It is the experience of many surgeons that such patients are very grateful for the relief of heartburn which had plagued them for years. Perhaps more patients should be considered for surgery, for provided the symptoms are certainly attributable to the hiatus hernia over $80 \%$ are completely relieved or greatly improved by operation. ${ }^{11} 12$

Dysphagia as a result of peptic oesophageal stricture is difficult to treat. Palmer managed all his patients by repeated dilatation. Though a patient's nutrition may be maintained by repeated bougienage, the relief of dysphagia is often far from complete, and this is not altogether surprising when the degree of structural damage and fibrotic narrowing is observed in a resected specimen. Most surgeons in Britain have favoured surgical treatment for peptic strictures of the oesophagus, with either resection with colonic ${ }^{13}$ or jejunal interposition, a lower partial gastrectomy, ${ }^{14}$ or even a bypass operation with subcutaneous colon between the oesophagus and the stomach.

Probably many patients with sliding hiatus hernia are never even referred to hospital: their symptoms are easily controlled by diet and alkalis. Only a more troubled minority find their way there, and only a small number of these will ever require operative treatment.

\section{Adenovirus Cystitis}

Patients with symptoms of acute cystitis but without detectable bacterial infection are a difficult clinical problem. ${ }^{1}$ Occasionally organisms such as trichomonas, T-strain mycoplasmas, candida, or the T.R.I.C. agent can be isolated, but usually no infectious cause for the symptoms can be found. Viruses of one kind or another can cause disease in most tissues and organs of the body, but none has so far been shown to produce symptoms in the urinary tract. Recently, however, a report from Sendai, Japan, has provided convincing evidence that viruses can cause acute cystitis. $^{2}$ In the cases described the virus was adenovirus type 11 .

Adenoviruses are best known as respiratory pathogens, but they also cause eye infections and probably play a part in some cases of mesenteric adenitis, intussusception, and gastroenteritis. $^{3}$ They are often found in the intestinal and respiratory tracts of healthy people as well as in those of patients, but have only rarely been reported-perhaps because rarely sought-in the urine. The isolation of adenovirus 11 from the urine of children with haemorrhagic cystitis is therefore of great interest.

Brit. med. F., 1968, 2, 192

2 Numazaki, Y., et al., New Engl. f. Med., 1968, 278, 700.

$s$ Potter, C. W., in Modern Trends in Medical Virology, ed. R. B. Heath and A. P. Waterson, 1967, 1, 162.

- Gresser, I., and Katz, S. L., New Engl. F. Med., 1960, 263, 452.

- Weller, T. H., and Neva, F. A., Proc. Soc. exp. Biol. (N.Y.), 1962, 111 215.

- Utz, J. P., and Szwed, C. F., Proc. Soc. exp. Biol. (N.Y.), 1962, 110, 841 .

' Utz, J. P., Houk, V. N., and Alling, D. W., New Engl. F. Med., 1964, $270,1283$.

s Gutenkuns:, R. R., and Heggie, A. D., New Engl. f. Med., 1961, 264, 374. 
The cases were seen over a period of 19 months in 11 children whose ages ranged from 7 to 15 years. Nine were boys. The symptoms were sudden onset of dysuria, frequency, and haematuria. The urine contained red cells, but leucocytes were relatively scanty and bacterial cultures were negative. Infection with adenovirus 11 was confirmed in all 11 children by the demonstration of rising titres of antibody. The virus was also isolated from nine out of ten urines examined. The significance of these results was confirmed by the failure to isolate adenovirus from the urine of healthy children as well as from children with various other diseases. However, infection with adenovirus 11 was common in Sendai at the time of the infections, since $75 \%$ of children over 10 years of age had antibody to it.

Viruses are excreted in the urine in various viral diseases, such as measles, ${ }^{4}$ rubella, ${ }^{5}$ and mumps. ${ }^{6}$ The viruria which accompanies acute febrile virus diseases is usually symptomless, though transient minor disturbance of renal-function tests was found in 20 patients with mumps who were subjected to detailed investigation. ${ }^{7}$ Symptomless viruria has also been reported in an outbreak of adenovirus infection among naval recruits, ${ }^{8}$ but adenoviruses are almost certainly a rare cause of cystitis.

Isolation of virus from urine samples is a relatively straightforward procedure. It is rarely, if ever, attempted in cases of non-bacterial urethritis and cystitis at present. Though routine virological examination of the urine in these conditions is probably not yet justified, further studies are clearly required to assess the role of viruses in patients presenting with dysuria where no bacterial cause is found.

\section{Recovery from Subacute Encephalitis}

The condition variously referred to as subacute sclerosing leucoencephalitis and subacute inclusion-body encephalitis is generally believed to be invariably fatal. The term "leucoencephalitis" in this disease is really a misnomer, as pathological evidence clearly indicates that the entire brain is affected. Consequently subacute sclerosing panencephalitis would seem to be a more satisfactory title.

The clinical picture of this disorder and the accumulating evidence to suggest that it may be due to measles virus have recently been considered in these columns. ${ }^{1}$ The condition usually presents in childhood or adolescence with insidious intellectual deterioration or psychological disturbances, though in some cases major epileptic convulsions may be present from the outset. As the disease progresses the patient becomes demented and usually develops spastic weakness of all four limbs, with myoclonic spasms occurring between 4 and 12 times a minute. The electroencephalogram is virtu-

Brit. med. 7., 1968, 1, 189.

- Cobb, W., and Hill, D., Brain, 1950, 73, 392.

- Osetowska, E., in Encephalitides:-Proceedings of a Symposium, Antwerp, 1959, 1961, ed. L. van Bogaert, J. Radermecker, J. Hozay, and A. Lowenthal, p. 414. Amsterdam.

- Cobb, W. A., and Morgan-Hughes, J. A., f. Neurol. Neurosurg.

Kurtzke

Minneap.), 1956, 6, 371

- Simpson, J. A., Lancet, 1961, 2, 685.

- Pearce, J. M. S., and Barwick, D. D., Brit. med. F., 1964, 2, 611. ally diagnostic in that it shows generalized and bizarre slowwave discharges of short duration occurring repetitively against a background of comparative electrical silence and often in time with the myoclonic jerks of the limbs. ${ }^{2}$ In most cases death occurs in from 3 to 18 months from the development of the first symptom, but, as E. Osetowska ${ }^{3}$ has pointed out, survivals for four or five years have been described.

Recently W. A. Cobb and J. A. Morgan-Hughes ${ }^{4}$ have produced evidence to suggest that in occasional cases the disease process may become arrested, leaving the patient with permanent gross disabilities, and yet more rarely still it seems that recovery may take place. J. F. Kurtzke, J. A. Simpson, and J. M. S. Pearce and D. D. Barwick ${ }^{7}$ have reported single cases with prolonged clinical remission in which the diagnosis seemed reasonably certain on clinical and electroencephalographic evidence. Cobb and Morgan-Hughes ${ }^{4}$ describe two patients, aged 21 and 18 years, each of whom had suffered slowly progressive and characteristic illnesses lasting respectively 15 months and 2 years, with subsequent gradual recovery. In both cases the gold colloidal (Lange) curve in the cerebrospinal fluid was typically paretic and the E.E.G. changes were characteristic. In one case a brain biopsy from the frontal lobe confirmed the diagnosis and in the second it was equivocal. It seems probable that in neither case did intellectual capabilities return completely to normal. It may be significant that both patients were somewhat older than the usual age at which this disease is known to occur, but, as the authors point out, many cases showing an onset in early adult life have progressed to a fatal termination. Though both patients showed intellectual deterioration during the progressive stage of the illness, it may also be significant that disturbances of motor function were comparatively slight. It would therefore seem that these two patients suffered from the disease in a mild form, which not only allowed them to survive but also to recover their previous intellectual abilities to some degree.

No effective treatment for this condition is known. But though it remains one of considerable gravity, it can no longer be regarded as being universally fatal.

\section{Student Participation}

Probably no other profession has more often examined the education of those who aspire to practise it than has medicine. International conferences, a Royal Commission, the General Medical Council, and innumerable individual writers have contributed to the discussion in recent years. Since the views of the teachers rather than those still being taught overwhelmingly predominate, it is a valuable corrective to hear from the students themselves. Some of their views are set out in the latest publication ${ }^{1}$ from the British Medical Students' Association.

Two main themes underlie the B.M.S.A. report, and both of them have a bearing on some of the causes of unrest in universities here and abroad. The first is that the student should be given the opportunity to play an active part in his own education, and not simply be offered a succession of lectures and demonstrations by a hierarchy of beings from somewhere near outer space. The second is that what is taught should all along be seen to be relevant to the student's 